\title{
Bandgaps and Surface Inter-Band States in Photocatalysts with High Energy Resolution EELS.
}

\author{
Qianlang Liu ${ }^{1}$, Liuxian Zhang ${ }^{1}$, Katia March $^{2}$, Toshihiro Aoki ${ }^{3}$ and Peter A. Crozier ${ }^{1}$
}

1. School for the Engineering of Matter, Transport and Energy, Arizona State University, Tempe Arizona 85287-6106

2. Laboratoire de Physique des Solides, Bâtiment 510, Université Paris-Sud, 91405 Orsay Cedex, France

3. LeRoy Eyring Center for Solid State Science, Arizona State University, Tempe, Arizona 85287, USA

Photocatalysts have potential applications for solar fuel generation through water splitting [1]. The bandgap and inter-band states of the semiconductors significantly affects the performance and efficiency of the catalysts. Recent advances in STEM EELS monochromation now allow for routine ultra-high energy resolution of $15 \mathrm{meV}$ or better in the low-loss region [2]. The ability to now correlate atomic structure and electronic structure in the low-loss and bandgap region of the energy-loss spectrum represents a powerful tool for characterization of electronic and optical properties of nanomaterial such as the high surface area, particulate systems that are generally used as catalysts. The band structure can vary among different nanoparticles depending on particle sizes, facets and also at the surfaces/interfaces of the semiconductors where charge transfer and photocatalytic reactions take place. With the innovation of high energy resolution EELS, it is possible to tackle the issues mentioned above by investigating the bandgap and the fine electronic structures inside the gap at the nano-level.

This study focuses on $\mathrm{TiO}_{2}$ and $\mathrm{Ta}_{2} \mathrm{O}_{5}$ which are both UV absorption photocatalysts due to their large bandgaps. $\mathrm{TiO}_{2}$ is relatively abundant with simple crystal structures while $\mathrm{Ta}_{2} \mathrm{O}_{5}$ is very efficient with more complicated structures. Four different samples were obtained: anatase $\mathrm{TiO}_{2}(\mathrm{HP}), \mathrm{Ta}_{2} \mathrm{O}_{5}(\mathrm{HP})$, $\mathrm{Ni} / \mathrm{TiO}_{2}(\mathrm{LP})$ and $\mathrm{NiO} / \mathrm{Ta}_{2} \mathrm{O}_{5}(\mathrm{LP}) . \mathrm{TiO}_{2}(\mathrm{HP})$ and $\mathrm{Ta}_{2} \mathrm{O}_{5}(\mathrm{HP})$ represent high purity $\mathrm{TiO}_{2}$ and $\mathrm{Ta}_{2} \mathrm{O}_{5}$ nanoparticles which were prepared following hydrothermal/solvothermal methods. $\mathrm{Ni} / \mathrm{TiO}_{2}$ (LP) was obtained first by wetness impregnation on low purity commercial anatase $\mathrm{TiO}_{2}$ which are hundreds of $\mathrm{nm}$ in size then reduced $@ 500^{\circ} \mathrm{C}$ in flowing $5 \% \mathrm{H}_{2} / \mathrm{Ar}$ for $2 \mathrm{hrs}$ [3]. It is used as a model of metal cocatalyst loaded on semiconductor to study the band structures at the interfaces. $\mathrm{NiO} / \mathrm{Ta}_{2} \mathrm{O}_{5}$ (LP) as a model of semiconductor-semiconductor photocatalyst was prepared also first by impregnation but then oxidized @ $500^{\circ} \mathrm{C}$ in flowing $\mathrm{O}_{2}$ for 2hrs [4]. Low-loss EELS was carried out on a monochromated and aberration-corrected NION microscope operated at $60 \mathrm{kV}$ with dispersions of $5 \mathrm{meV}$ or $2 \mathrm{meV}$ per channel. The energy resolution was better than $25 \mathrm{meV}$.

Fig. 1 shows the bandgap edges of $\mathrm{Ta}_{2} \mathrm{O}_{5}(\mathrm{HP})$ and $\mathrm{TiO}_{2}(\mathrm{HP})$ acquired under aloof beam conditions in which the electron beam was positioned at about $5 \mathrm{~nm}$ away from the particle surfaces. The measured values of $\mathrm{Ta}_{2} \mathrm{O}_{5}(\mathrm{HP})$ and $\mathrm{TiO}_{2}(\mathrm{HP})$ bandgap from more than 6 different spectra are $4.50 \mathrm{eV} \pm 0.02 \mathrm{eV}$ and $3.60 \mathrm{eV} \pm 0.01 \mathrm{eV}$ respectively. The bandgap is measured by extrapolating the straight portion of the fitted curve to the $x$ axis. For anatase, the EELS measurement of $3.60 \mathrm{eV}$ is larger than the wellknown $\sim 3.2 \mathrm{eV}$ but close to the recent theoretical calculation and experimental data [5]. Fig.1b also shows the bandgap of anatase increases to $3.71 \pm 0.03 \mathrm{eV}$ as the $\mathrm{Ti}$ in the particle was reduced from $\mathrm{Ti}^{+4}$ to $\mathrm{Ti}^{+3}$ by the electron beam (Figure $1 \mathrm{~b}$ insertion) which is contradictory to conventional optical measurements showing a narrower bandgap for reduced $\mathrm{TiO}_{2}$. The reason is not clear at this stage. On Fig. 2, inter-band states were clearly observed when the beam was on the surfaces of bare $\mathrm{Ta}_{2} \mathrm{O}_{5}$ and $\mathrm{TiO}_{2}$ of the $\mathrm{NiO} / \mathrm{Ta}_{2} \mathrm{O}_{5}(\mathrm{LP})$ and $\mathrm{Ni} / \mathrm{TiO}_{2}(\mathrm{LP})$ samples. Distinctive interstates peaks were at $1.13 \mathrm{eV}$, 
$2.14 \mathrm{eV}$ and $2.66 \mathrm{eV}$ for $\mathrm{Ta}_{2} \mathrm{O}_{5}$ and $2.08 \mathrm{eV}, 2.37 \mathrm{eV}$ and $2.85 \mathrm{eV}$ for $\mathrm{TiO}_{2}$. The peaks are only observed on the surface of the particles and they vanish when the beam is in the bulk $\mathrm{Ta}_{2} \mathrm{O}_{5} \mathrm{or} \mathrm{TiO}_{2}$. Those states are believed to be related to the oxygen vacancies produced from the high temperature reduction and/or impurities segregated to surfaces in the commercial $\mathrm{TiO}_{2}$ or $\mathrm{Ta}_{2} \mathrm{O}_{5}$ after high temperature heat treatment. The energies of these inter-band states vary among different particles depending on their local morphology and impurity concentrations. Peaks associated with different oxygen vacancy concentrations were also observed. More experimental data with theoretical simulation to explore the complicated electronic band structures of these photocatalyst materials will be presented.

\section{References:}

[1] Fujishima, A.; Honda, K. Nature 238 (1972), 37.

[2] O.L. Krivanek et al, Nature 514 (2014), 209.

[3] L. Zhang et al, J. Phys. Chem. (under review)

[4] Q. Liu et al, Appl. Catal. B: Environ.172 (2015), 58.

[5] M. Landmann et al, J. Phys: Condens. Matter 24 (2012), 195503

[6] The support from US Department of Energy (DE-SC0004954) and the use of NION microscope at John M. Cowley Center for HR Microscopy at Arizona State University is gratefully acknowledged.
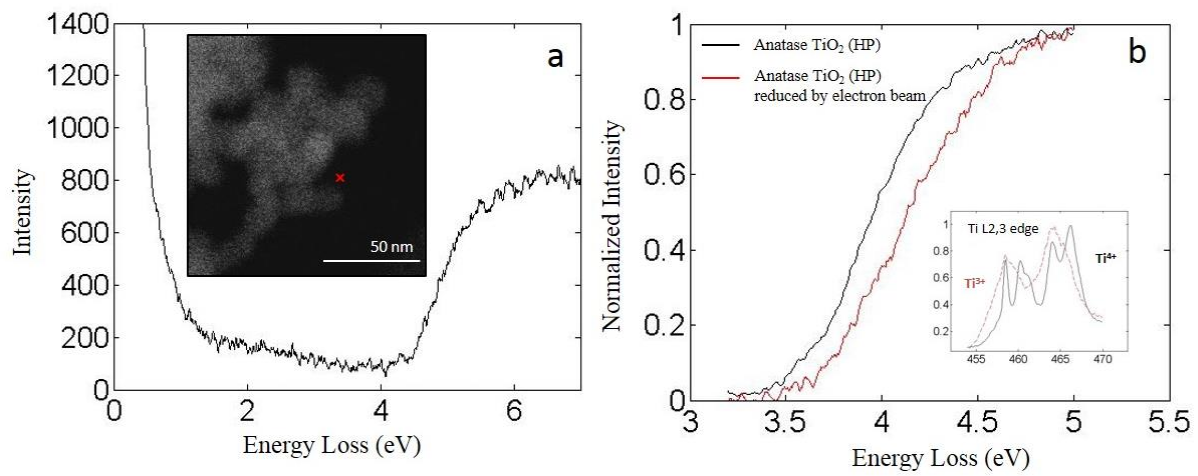

Figure 1: a) Low-loss EELS with insertion of STEM image showing beam was near surface of $\mathrm{Ta}_{2} \mathrm{O}_{5}$ (HP) particles; b) Bandgap edge from anatase $\mathrm{TiO}_{2}(\mathrm{HP})$ with insertion of $\mathrm{Ti}_{2,3}$ edges before and after reduction by electron beam.
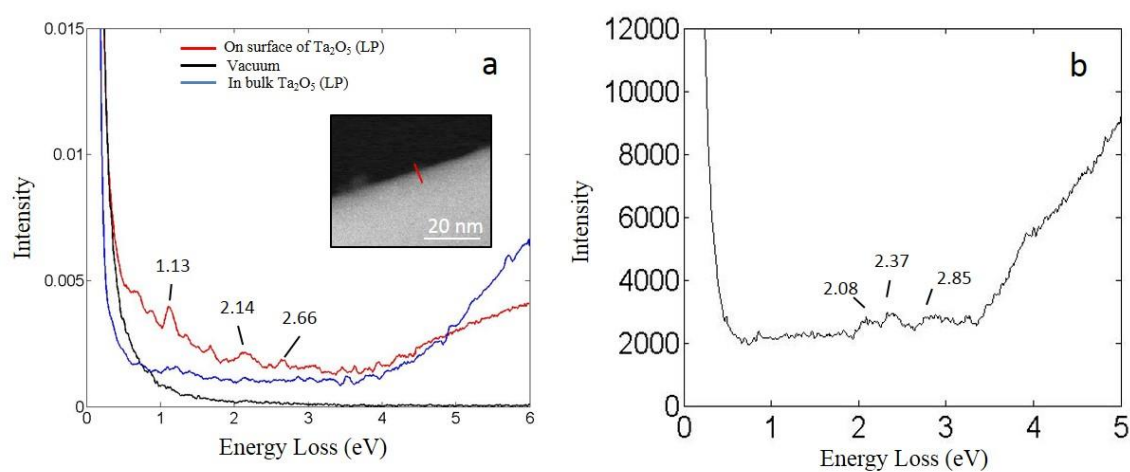

Figure 2: a) Inter-band states on surface of $\mathrm{Ta}_{2} \mathrm{O}_{5}(\mathrm{LP})$ and low-loss EELS of vacuum. The insertion shows where the surface spectra were taken; b) Inter-band states on surface of $\mathrm{TiO}_{2}$ from $\mathrm{Ni} / \mathrm{TiO}_{2}(\mathrm{LP})$ sample. 